\title{
Stopping smoking advice given by practice assistants after routine cervical screening in general practice: a qualitative exploration of potential barriers and enablers.
}

Marthe B.L. Mansour ( $\nabla$ m.b.mansour@amsterdamumc.nl )

AMC https://orcid.org/0000-0003-4991-9520

Matty R. Crone

Leids Universitair Medisch Centrum

Henk C. van Weert

AMC

Niels H. Chavannes

Leids Universitair Medisch Centrum

Kristel M. van Asselt

AMC

\section{Research article}

Keywords: Smoking cessation, cervical cancer screening, practice assistant, primary care, qualitative research, focus group study

Posted Date: October 29th, 2019

DOI: https://doi.org/10.21203/rs.2.16494/v1

License: (c) (i) This work is licensed under a Creative Commons Attribution 4.0 International License.

Read Full License 


\section{Abstract}

Background Cervical screening could be an appropriate moment to provide female smokers with stopping smoking advice and support. In Dutch general practice cervical smears are performed by practice assistants. The aim of this study was to identify potential barriers or enablers for a stopping smoking strategy performed by trained practice assistants after routine cervical screening. The strategy consists of brief stopping smoking advice and is based on the Ask-Advise-Connect approach.

Methods Three focus group meetings were held with 10 practice assistants, 3 nurses, and 6 general practitioners. We analysed data using thematic analysis. Identified factors are presented within the framework of the Social Ecological Model.

Results Potential influential factors were identified at individual, interpersonal, and workplace levels. At the individual level: practice assistants did not see themselves as having a professional role in a smoking cessation program. While they could register smoking status, they were reluctant to provide advice. However, practice assistants valued having advice at hand in order to make relatively young female smokers aware of the health risks At the interpersonal level: practice assistants thought that their relationship with the women would change if they gave stopping smoking advice. Moreover, the assistant's own attitude to smokers and her beliefs about the smoker's willingness to change behaviour could influence the relationship. At the workplace level: the availability and motivation of nurses might hamper referral. The general practitioners' opinion about primary prevention and smoking cessation could influence the amount of support given to practice assistants when it comes to providing stopping smoking advice.

Conclusions At individual, interpersonal, and workplace levels, several factors could influence the provision of a stop smoking strategy by a practice assistant. These factors could be used to design a behavioural change intervention to be provided by practice assistants after cervical cancer screening.

\section{Background}

Opportunities to give stopping smoking advice are underused in general practice (1), even though guidelines recommend that all smokers should be given relevant advice, and especially those smokers at high risk of, or complaints related to, tobacco-related disease (2). Smokers without signs or symptoms related to smoking are less likely to be given stopping smoking advice $(1,3)$. This is a missed opportunity, because the preventive impact of smoking cessation on tobacco-related disease and early death increases if smokers quit at a younger age (4). Cervical cancer screening could be an opportunity to provide women with stopping smoking advice and support, as the profits of quitting on this relatively young age are big. $(5,6)$. In the Netherlands, women aged 30-65 years are invited for cervical screening at their general practice. In this age category, $16.3-17.4 \%$ of women are daily smokers (7).

In the Netherlands, the national cervical cancer screening programme is carried out in general practice and the smear is performed by a practice assistant, while stopping smoking advice or support is mainly 
delivered by general practitioners (GPs) and/or by qualified nurses. Although studies on the provision of stopping smoking care by auxiliary healthcare workers (such as practice assistants) are sparse, there is evidence that advice given by the practice assistant is as effective as interventions of doctors and nurses (8-12). As practice assistants are employed in most Dutch general practices, they could have a potential role in registering smoking status, giving stopping smoking advice, or referring patients on to cessation counselling.

There is, however, no evidence on the effectiveness of this approach in women who undergo a routine cervical smear. In a cluster randomized trial, we plan to investigate the effect of a stopping smoking strategy delivered by practice assistants after cervical screening in general practice. The strategy is based on the Ask-Advise-Connect method (13). The steps consist of: 1. Ask about smoking status, 2. Provide brief stopping smoking advice, and 3. Actively refer to the support given by the nurse or GP. When designing and implementing complex interventions, such as health behaviour interventions, it is important to identify barriers and enablers among the health professionals involved. Qualitative research methods are the most suitable to explore potential barriers and enablers based on professionals' views $(14,15)$. Here, we identified potential barriers or enablers to the delivery of stopping smoking advice by a practice assistant.

\section{Methods}

\section{Study design and participants}

Focus group meetings were held with practice assistants (PAs), nurses and general practitioners (GPs) to obtain information from different perspectives. We assumed two main aspects of this strategy to differ from care as usual: i) the advice is given by a practice assistant, ii) the advice is given after a cervical smear. As the strategy mainly involves practice assistants, we aimed to include relatively more assistants. Purposive sampling ensured a variation in age, work experience, and type of general practice. Participants were invited via a recruiting message on social media, via e-mail, and via recruiting talks after training programmes. Four participating assistants had recruited female smokers to participate in a separate qualitative interview study and had experience in asking women about their smoking status after a smear. All participants were Dutch and currently employed in a Dutch general practice. Written consent was obtained. Participants received a gift voucher (€25) as compensation for their time.

\section{Data collection}

Three focus group meetings were held between December 2016 and March 2017. In total 10 practice assistants, 3 nurses, and 6 general practitioners participated. A focus group guide was developed to stimulate discussion and explore the following topics: 1) Organization, tasks, and experiences of participants with smoking cessation in general practice, 2) Attitudes towards stopping smoking advice given by a practice assistant after cervical screening, and 3) Expected barriers to, and enablers of, this approach. At the start of each focus group meeting, the outline of the strategy (Ask-Advise-Connect) was 
explained (see Additional file 1).. Focus groups were moderated by two researchers (KvA and MC) with experience in qualitative methods. One researcher (MM) acted as an observer and did not participate in the group discussions. The meetings lasted 70-90 minutes. Data were collected until no new themes emerged.

\section{Analysis}

Focus group meetings were audio recorded, transcribed verbatim, reviewed for accuracy, and imported into MAXQDA 12. Thematic analysis was used, going from open to analytical coding (16) and with an iterative process of data collection and analysis. KvA and MM coded the first focus group meeting independently; MM coded the other two. Three researchers (KvA, MC, MM) read all transcripts and discussed codes, categories, and themes in detail. Discrepancies were discussed until consensus was reached. We sought to explore barriers and enablers with a focus on the practice assistant. Factors were categorized based on their level of influence; for this purpose, we used a social-ecological framework (17). We identified factors at the individual level (practice assistant), interpersonal level (interaction between assistant and female smoker), and organizational level (the work environment). We report our study using the 32-item checklist of consolidated criteria for reporting qualitative research (COREQ) (18).

Box 1-Dutch general practice: practice assistants and nurses

Dutch general practice is comparable to primary care in the United Kingdom, Canada, and Australia. The core of a Dutch general practice consists of a GP, a practice assistant, and-in most practices - a qualified nurse. In countries with similar healthcare systems, PAs are known as 'medical assistants', 'healthcare assistants' or 'allied healthcare personnel'. The knowledge, skills, and competence of PAs vary in EU member states (19), which can partially explain differences in the deployment of PAs between countries. An average Dutch general practice employs a 1.94 full-time equivalent PA and a $0.63 \mathrm{fte}$ nurse (20).

Qualified nurses provide protocol-based care and are specialized in chronic care management, typically for patients with diabetes, COPD / asthma, cardiovascular diseases, or vulnerable elderly (21). For example, the nurse can address issues such as medication use, but also engages in lifestyle counselling such as smoking cessation. Job qualifications for practice assistant differ from those of a qualified nurse. Activities for assistants vary according to practice needs. In the job description published by the Dutch National Association of General Practitioners (Landelijke Huisartsen Vereniging, LHV),, an assistant's tasks broadly covers the intake or triage of patients and providing assistance for medical and administrative tasks. Many nurses work more or less independently (20), and many have their own consultations, for taking cervical smears or measuring blood pressure. In general terms, nurses provide care for specific patient groups in general practice and typically do not engage in administrative tasks. In contrast, in some practices assistants also provide chronic care management or other case-based tasks which can overlap with those of a qualified nurse.

\section{Results}


Participant characteristics

Participant characteristics are listed in Table 1.

Factors of influence

Factors are presented at the level of influence: the individual level (namely, the practice assistant), the interpersonal level (interaction between practice assistant and female smoker), organizational level (work environment, e.g. the general practice). For each level, we indicate at which step of the stopping smoking strategy the factors are applicable: Ask, Advise and/or Connect.

Individual level-the practice assistant

Factors apply to 'Ask' and 'Advise'.

\section{The practice assistant's professional role}

Practice assistants (PAs) did not consider themselves to have a professional role in stopping smoking care, considering that such advice was part of the nurses' core business. None of the assistants routinely provided stopping smoking advice and support. Moreover, most assistants did not know how or where smoking status was registered in the electronic medical record. A few assistants registered smoking status on some occasions, such as with new patients or during blood pressure control.

\#22-PA:[at our practice] a person's smoking status is not registered, at least it can't be seen immediately. Actually, we have little to do with it. Well, apart from when they say that they want to stop smoking and ask questions about how to go about it. Then we refer the patient to the practice nurse.

With regard to the ask-advise-connect steps, practice assistants thought that asking about and registering a woman's smoking status would not be a problem: it was considered to be an easy extra question and could be added to the standard questionnaire that is taken before a smear. General practitioners (GPs) and nurses agreed with this viewpoint.

Some assistants thought that giving actual stopping smoking advice would be challenging as it requires additional time, skills, and knowledge. On the other hand, assistants thought that they had more time and were more approachable for patients than GPs and nurses.

Some of the practice assistants were willing to be more involved in stopping smoking care but did not know how to do so. Several assistants sometimes talked briefly about lifestyle advice during their consultations, such as talking about stress, diet, or in some cases smoking behaviour, or referred a smoker to the nurse. None of the assistants had knowledge about the actual content of stopping smoking care.

\#6-PA: In our practice, cardiovascular patients see the nurse once a year. Then it's handy if everything is registered, such as lifestyle and smoking. You can refer to this at the 3-monthly check-up with the practice 
assistant. I do that as well, such as "Last time you had lost $5 \mathrm{~kg}$, is it still off?" More this type of thing. These conversations or chats take 10 minutes.

Attitude towards the cervical smear as a teaching moment

Nearly all focus group participants agreed that smoking had to be associated with cervical cancer in order that the smear test could be considered a legitimate teaching moment. Most participants were not aware of the correlation of smoking and the development of cervical abnormalities. One GP described stopping smoking advice after cervical screening as misuse of the smear for a good purpose. On the other hand, practice assistants and two GPs considered it important to make women aware of the health risks of smoking.

Interpersonal level -interaction between practice assistant and female smoker

Factors apply to 'Advise' and 'Connect'.

Do not overwhelm

Focus group participants thought it necessary to explain why they asked women about their smoking habit just after a smear test. Most practice assistants (PAs) noticed that women were tense before a smear and would not want then to become more stressed.

\#16-PA: First, they are in a vulnerable position, literally. The explanation that they probably need at that moment. What does it [smoking status] have to do with it [smear test]? And their anxiety and stress at that moment.

The practice assistants anticipated that women would ask why they were being asked about smoking at that moment, and they wanted to have a ready answer. A few assistants thought they could easily explain why, because of the link between smoking and cancer. These assisatnts had previously participated in a training course about the cervical smear programme (where risk factors for cervical cancer development were discussed).

\section{Challenging switch from smear to smoking}

All participants believed addressing health behaviour is difficult and time consuming. In general, it was perceived as more appropriate and easier to discuss smoking cessation if women could be told of the connection between smoking and cervical cancer.

The four practice assistants who had briefly talked about smoking after a smear test said that smokers reacted positively and asked why smoking was being discussed. Importantly, these assistants considered it challenging to switch from taking a smear to talking about smoking cessation. Having enough time and experience performing smears were considered essential to feeling confident about performing these activities. 
\#4-PA: I've asked the question a couple of times, and it's certainly a change going from doing a smear test to asking about smoking ... I mainly say that we are carrying out research. So I don't immediately offer stopping smoking advice. It is surprising how people, women, react. Actually, it went better than expected.

Beliefs about smokers and their response to stopping smoking advice

Smoking was considered an addiction, but from their comments we deduced that participants would not necessarily approach smokers as such. Some practice assistants said that smoking is the smoker's responsibility and that failing to quit is a rational choice. Focus group participants agreed that the smoker's motivation to quit is key.

The participants had different expectations about the acceptability and effectiveness of the stopping smoking strategy. Practice assistants related this to the health status of female smokers, they expressed various views, such as: "The enhanced risk of cancer in smokers could stimulate them to quit", and: "Women could be receptive to quit advice because many of them have (want to have) children", or: "Having an aberrant smear result would make women more receptive to quit advice", versus: "Women who visit for the smear and have not experienced any major health-related problems will not change their behaviour"..

Referring to their experience with patients who were smokers or overweight, two GPs commented that patients are willing to have a conversation about their lifestyle because they want to be reassured, not because they want to change their behaviour. Acceptance of a conversation is not a guarantee for action. \#8-GP:If they smoke, then they want to hear that they don't have cancer. On the other hand, I don't think that they want to stop [smoking] to avoid it. They just want to hear that they don't have it-they can then go on smoking. Stopping is a stage further, but this is true for all addictions.

The absence of health-related problems might imply an absence of motivation to stop smoking, which could lead to high no-show rates for smoking cessation counselling.

Workplace-organization and attitudes at the general practice level

Factor applies to 'Connect'.

Nurse's interest and availability

The nurse was considered a potential bottleneck as her availability might limit referral. The nurse's motivation to guide this support was expected to influence the quality of support delivered. Even though the nurses who participated in our study provided smoking cessation advice, some participants reported that the nurse working in their practice was not at all motivated to provide stopping smoking care.

\#21-PA:It's noticeable that people like it if they immediately get an appointment. "An appointment, that's OK". Because our practice nurse is only here on Mondays and Tuesdays 
\#24-PA:But I think she doesn't like to give stopping smoking advice

\#18-GP:The same in our practice; she didn't choose to do it.

Factors apply to the delivery of the strategy as a whole.

'General practitioner's view on prevention

Practice assistants expected the general practitioner (GP) to lead the way when it comes to smoking cessation and prevention strategies. Some assistants argued that prevention is part of primary care, others wanted to be aware of health behaviour risks in order to be able to provide patients with specific information about prevention. However, despite their own views, practice assistants would follow the course set by the GP.

\#21-PA:I talked to the boss about it once. He said: "You can lower cholesterol levels by $40 \%$ if you stop smoking". And then I said: "Well, then you've got something to do'. Then he said: "But people have to choose to do so" I was shocked about this, that you could influence cholesterol levels by $40 \%$. I think that he was setting out the strategy. I was looking for-what do we think about this? As a practice?

Within-practice approach to stopping smoking care

Some practices adopted more of a 'reactive' approach to smokers-the patient should ask for advice and support. In these practices, smoking status was not reported consistently. General practitioners (GPs) in these practices did not consider primary prevention to be their task, viewing it a task imposed by the government.

Other practices had a more 'proactive' policy, with the smoking status of patients being routinely recorded. All newly registered smokers were offered stopping smoking support and quitters were actively monitored. GPs in these practices considered prevention to be a GP's tasks: it is important to warn patients, to make them aware of health risks. GPs should want to improve their patients' health.

\#10-GP: As doctor, I see the importance of primary prevention in this relatively young group of people. I see that as a positive aspect of being a GP. That you can pick out certain patients and send them to the practice nurse and ask: do you smoke-yes or no? If you smoke, do you want to do something about it?

\section{Discussion}

\section{Summary of findings}

In this focus group study, we identified potential barriers or enablers to the delivery of a stopping smoking strategy by a practice assistant after routine cervical screening in general practice.

At the individual level: practice assistants did not consider themselves to have a role in smoking cessation. They believed it is feasible to register smoking status, but felt reluctant to give advice. 
However, practice assistants valued having advice at hand in order to make relatively young female smokers aware of the health risks.

At the interpersonal level: practice assistants expected that their relationship with the female patient would change if they provided stopping smoking advice. However, this might not necessarily be the case if they could explain why they were giving stopping smoking advice, provided that they had enough time and experience. The attitude of assistants towards smokers and their beliefs about smokers' motivation to change behaviour could also influence the relationship.

At the workplace level: The availability and motivation of the nurse could limit referral opportunities. The general practitioner's opinion about primary prevention and smoking cessation could affect the support given to the practice assistant when it comes to giving stopping smoking advice.

\section{Comparison with existing literature}

The practice assistants who took part in our focus group meetings had little or no experience in providing stopping smoking advice-they were unsure about their abilities to provide this advice and assigned this role to the nurse. General practitioners (GPs) and nurses were also not sure whether assistants would be capable of providing this advice. This ambivalence to the provision of stopping smoking advice by practice assistants stands in contrast with results from studies showing that advice or counselling given by assistants is at least as effective as similar care provided by registered nurses (8-10). It also contrasts with the findings of qualitative studies conducted in the $\mathrm{U}$. K. that report that GPs and nurses consider smoking cessation to be a suitable task for practice assistants $(22,23)$. There have been no reports on the professional role, self-efficacy, or training experience of assistants involved in stopping smoking care.

Even though practice assistants were ambivalent about their ability to deliver stopping smoking advice, they valued being able to make women aware of the health risks of smoking. Certain assistants expressed the wish to learn how to provide lifestyle advice-they wanted training to acquire more knowledge and skills to provide stopping smoking advice after a smear test. Two qualitative studies involving practice assistants in general practice showed that assistants had a positive attitude to skills development, especially the improvement of patient-communication skills, and career development gave them more overall job satisfaction $(24,25)$. A primary care study reported that health promotion activities provided by practice assistants resulted in more referrals and stressed the importance of training and changes in practice culture to improve risk behaviour outcomes (26). Likewise, the need for training was noted in two reviews of barriers and facilitators in the delivery of primary or cardiovascular prevention in primary care $(27,28)$. Butler et al. found that training primary care health professionals in behaviour change counselling increased patients' intention and attempts to change (29). The participants in our study had different expectations about the motivation of smokers to change their behaviour. Indeed, professionals' beliefs (and the attitudes of their colleagues) towards primary prevention and health 
promotion have been identified as factors that can impact on the delivery of such interventions $(27,28$, 30).

Cancer screening participants might be more receptive to health behaviour interventions than people who do not participate in cancer screening. A teaching moment can be created, based on screening participants' health behaviour and the disease for which they are screened (5). A recent cross-sectional survey study assessed willingness to receive lifestyle advice at the time of cancer screening. Of cervical screening participants $(n=768), 78.9 \%$ were willing to receive advice (31). The expectations of health professionals tend to differ from those of patients. Participants in our study were unsure whether the cervical smear is a legitimate teaching moment (32). The smear differs from other teaching moments, such as a cardiovascular disease consult, considered to be appropriate because there is a clear relationship with smoking (33). Another cancer screening programme used for stopping smoking advice is lung cancer screening. Although there is a clear link between smoking and lung cancer, professionals are also ambivalent about lung cancer screening as a teaching moment to enhance motivation to stop smoking, as this was considered as, capitalizing on the moment (next to missing the opportunity due to time constraints, knowledge or resource constraints, or lack of success with previous attempts) (34).

Participants in our study mentioned that having enough time and experience would make it easier to switch from taking a smear to talking about smoking. Time and knowledge are known constraining factors in the provision of primary prevention in primary care $(27,28)$. Hall et al. considered stopping smoking advice by a nurse after a smear test feasible in terms of available time; time taken to complete the smear consultation in the intervention arm of a randomised trial conducted by Hall et al. took five minutes more in comparison to the control arm (6).

We found that a stopping smoking strategy needs support from all health professionals involved. Practice assistants tend to follow the course set by the GP. Nurses work under the authority of the GP (35), but they can in certain cases act as case managers for lifestyle counselling (36). If after an advice of the practice assistant a smoker is motivated to quit, he/she will frequently be referred to the nurse for smoking cessation counselling. Both the GP's views and the nurse's motivation and availability to provide stopping smoking care are likely to influence the delivery of an intervention by the practice assistant in terms of support, priority, and availability of time or resources.

GPs held different views on prevention, with either a reactive or proactive approach towards smokers. Currently, a debate exists among GPs in the Netherlands whether individual stopping smoking advice falls under the domain of the general practitioner. In a recent qualitative study Australian GPs reported a conflicting role in discussing lifestyle behaviour as they perceived it as their primary role to address the patients' current complaints, but they also believed they should promote patients' health beyond this complaint (37).

There are various determinants for the successful implementation of healthcare innovations $(30,38)$. We found a number of factors that overlapped the domains of professional role, knowledge and skill, beliefs about capabilities, beliefs about the consequences of innovation, social support, organization, and the 
patient (30). The Common Framework of Implementation Research (CFIR) provides a set of constructs for effective implementation, both for the design and evaluation of an intervention. Our findings mainly fall under the CFIR construct domains of 'Inner Setting' and 'Characteristic of Individuals' (38).

\section{Strengths and limitations}

We involved three different types of primary care health professionals, which enabled an interactive exploration of their views on a stopping smoking strategy. This qualitative study was performed in preparation for a cluster randomized trial studying the effect and acceptability of this stopping smoking strategy. Four participating practice assistants had been taught how to discuss smoking cessation after a smear test, so we cannot make comparisons with care as usual in general practice. The study participants might have had a positive attitude towards stopping smoking care, whereas more sceptical professionals may not have responded to the request for study participation. This study adds to the body of evidence regarding the role, needs, and attitudes of practice assistants to the delivery of a stopping smoking strategy in general practice, and to the views of health professionals about the combination of stopping smoking advice and cervical cancer screening.

\section{Conclusions}

In this focus group study, we identified potential barriers or enablers to the implementation of a stopping smoking strategy delivered by a practice assistant after a cervical smear test in general practice. Factors were identified at the individual, interpersonal, and general practice level and impact on the different steps of brief stop smoking advice: Ask, Advise, Connect. Results can be used to develop a stopping smoking intervention to be delivered by a practice assistant or a similar intervention combined with cervical cancer screening.

\section{Tables}

TABLE 1. Participant characteristics 


\begin{tabular}{|c|c|c|}
\hline \multicolumn{2}{|l|}{ Characteristics } & \multirow{2}{*}{$\begin{array}{l}\text { Participants } \\
(\mathbf{n}=19) \\
17 / 19\end{array}$} \\
\hline Gender & Female & \\
\hline & Male & $2 / 19$ \\
\hline \multicolumn{2}{|l|}{ Age } & $27-60$ yrs. \\
\hline \multirow[t]{3}{*}{ Profession } & Practice assistant & $10 / 19$ \\
\hline & Nurse & $3 / 19$ \\
\hline & General practitioner & $6 / 19$ \\
\hline \multirow[t]{3}{*}{ Geographical location of general practice } & Major city & $11 / 19$ \\
\hline & Urbanized region & $6 / 19$ \\
\hline & Rural/village & $2 / 19$ \\
\hline \multirow[t]{2}{*}{ Smoking status $^{\mathrm{a}}$} & Ex-smoker & $10 / 19$ \\
\hline & Never-smoker & $9 / 19$ \\
\hline \multirow[t]{3}{*}{ Years of working experience ${ }^{b}$} & 1 & $2 / 19$ \\
\hline & $2-10$ & $4 / 19$ \\
\hline & $>10$ & $13 / 19$ \\
\hline \multirow[t]{2}{*}{ Attended courses } & Stopping smoking support & $5 / 19^{c}$ \\
\hline & Motivational interviewing & $5 / 19^{d}$ \\
\hline
\end{tabular}

a 3 categories: Current-smoker, Ex-smoker and Never-smoker.

b Total number of working years as a practice assistant / nurse / general practitioner.

C No practice assistants previously participated in a course on providing stopping smoking support.

d One practice assistant previously participated in a course on motivational interviewing techniques

\section{Declarations}

\section{List of abbreviations}




\section{Ethics approval and consent to participate}

Official approval of this study was waived by the Medical Ethics Review Committee of the Academic Medical Centre in Amsterdam, the Netherlands (reference: W16_312 \#16.367). Written consent was obtained from all study participants.

\section{Consent for publication}

We confirm that we have obtained consent to publish from all focus group participants to report anonymized participant data from the focus groups.

\section{Availability of data and materials}

An example from the focus group guide and topics used is available in the additional files, this is a summary and English translation of the original focus group guide in Dutch. The transcripts (in Dutch) from all three focus groups are not publicly available due to protection of participant confidentiality.

\section{Competing interest}

The authors have no competing interests to declare.

\section{Funding}

This project was funded by a grant from the Dutch Cancer Society (UVA 2015-7853).

\section{Author's contributions}

All authors contributed to the design of the study. MM was responsible for recruitment of study participants, KvA and MC conducted the focus groups. MM performed the and analysis with input from KvA and MC. MM drafted the manuscript, which KvA and MC commented on and edited; the final manuscript was read and approved by all authors.

\section{Acknowledgments}

We wish to thank the health professionals who participated in the focus groups. Also, we are grateful to Sonja Jerak-Zuiderent for her useful comments and input. 


\section{Additional files}

- 'Box 1 - Dutch general practice: practice assistants and nurses': on page 5 of this manuscript

- 'Table 1-participant characteristics': on page 12 of this manuscript

- 'Additional file 1-focus group guide and topics used'

\section{References}

1.Stead M, Angus K, Holme I, Cohen D, Tait G, Team PER. Factors influencing European GPs' engagement in smoking cessation: a multi-country literature review. Br J Gen Pract. 2009;59(566):682-90.

2.Chavannes NH, Meijer E, Wind LA, van de Graaf RC, Rietbergen C, Croes EA. Herziene richtlijn 'Behandeling van tabaksverslaving en stoppen met roken ondersteuning'. Ned Tijdschr Geneeskd. 2017:161:D1394.

3.Borland R, Li L, Driezen P, Wilson N, Hammond D, Thompson ME, et al. Cessation assistance reported by smokers in 15 countries participating in the International Tobacco Control (ITC) policy evaluation surveys. Addiction. 2012;107(1):197-205.

4.Pirie K, Peto R, Reeves GK, Green J, Beral V. The 21st century hazards of smoking and benefits of stopping: a prospective study of one million women in the UK. Lancet. 2013;381(9861):133-41.

5.Senore C, Giordano L, Bellisario C, Di Stefano F, Segnan N. Population based cancer screening programmes as a teachable moment for primary prevention interventions. A review of the literature. Front Oncol. 2012;2:45.

6.Hall S, Reid E, Ukoumunne OC, Weinman J, Marteau TM. Brief smoking cessation advice from practice nurses during routine cervical smear tests appointments: a cluster randomised controlled trial assessing feasibility, acceptability and potential effectiveness. Br J Cancer. 2007;96(7):1057-61.

7.CBS Leefstijlmonitor 2017 [https://www.cbs.nl/nl-nl/maatwerk/2018/15/leefstijl-2017], 2017.

8. Hiscock R, Murray S, Brose LS, McEwen A, Bee JL, Dobbie F, et al. Behavioural therapy for smoking cessation: the effectiveness of different intervention types for disadvantaged and affluent smokers. Addict Behav. 2013;38(11):2787-96.

9.Faulkner K, Sutton S, Jamison J, Sloan M, Boase S, Naughton F. Are Nurses and Auxiliary Healthcare Workers Equally Effective in Delivering Smoking Cessation Support in Primary Care? Nicotine Tob Res. 2016;18(5):1054-60.

10.Katz DA, Brown RB, Muehlenbruch DR, Fiore MC, Baker TB, Group ASCGS. Implementing guidelines for smoking cessation: comparing the efforts of nurses and medical assistants. Am J Prev Med. 
2004;27(5):411-6.

11.Stead LF, Buitrago D, Preciado N, Sanchez G, Hartmann-Boyce J, Lancaster T. Physician advice for smoking cessation. Cochrane Database Syst Rev. 2013(5):CD000165.

12.Rice VH, Heath L, Livingstone-Banks J, Hartmann-Boyce J. Nursing interventions for smoking cessation. Cochrane Database Syst Rev. 2017;12:CD001188.

13.Vidrine JI, Shete S, Cao Y, Greisinger A, Harmonson P, Sharp B, et al. Ask-Advise-Connect: a new approach to smoking treatment delivery in health care settings. JAMA Intern Med. 2013;173(6):458-64.

14.Moore GF, Audrey S, Barker M, Bond L, Bonell C, Hardeman W, et al. Process evaluation of complex interventions: Medical Research Council guidance. BMJ. 2015;350:h1258.

15.Campbell NC, Murray E, Darbyshire J, Emery J, Farmer A, Griffiths F, et al. Designing and evaluating complex interventions to improve health care. BMJ. 2007;334(7591):455-9.

16.Braun V, Clarke V. Using thematic analysis in psychology. Qualitative Research in Psychology. 2006(3(2)): 77-101.

17.McLeroy KR, Bibeau D, Steckler A, Glanz K. An ecological perspective on health promotion programs. Health Educ Q. 1988;15(4):351-77.

18.Tong A, Sainsbury P, Craig J. Consolidated criteria for reporting qualitative research (COREQ): a $32-$ item checklist for interviews and focus groups. Int J Qual Health Care. 2007;19(6):349-57.

19.Kroezen M, Schafer W, Sermeus W, Hansen J, Batenburg R. Healthcare assistants in EU Member States: An overview. Health Policy. 2018;122(10):1109-17.

20.Landelijke Huisartsen Vereniging. <Handleiding FWHZ_Functiewaardering Huisartsenzorg.pdf>, 2019.

21.Nederlandse Zorgautoriteit. <Praktijkkostenonderzoek huisartsen 2015.pdf>, 2017.

22.Petrova M, Vail L, Bosley S, Dale J. Benefits and challenges of employing health care assistants in general practice: a qualitative study of GPs' and practice nurses' perspectives. Fam Pract. 2010;27(3):303-11.

23.Bosley S, Dale J. Healthcare assistants in general practice: practical and conceptual issues of skill-mix change. Br J Gen Pract. 2008;58(547):118-24.

24.Gensichen J, Jaeger C, Peitz M, Torge M, Guthlin C, Mergenthal K, et al. Health care assistants in primary care depression management: role perception, burdening factors, and disease conception. Ann Fam Med. 2009;7(6):513-9. 
25.Vail L, Bosley S, Petrova M, Dale J. Healthcare assistants in general practice: a qualitative study of their experiences. Prim Health Care Res Dev. 2011;12(1):29-41.

26.Ferrer RL, Mody-Bailey P, Jaen CR, Gott S, Araujo S. A medical assistant-based program to promote healthy behaviors in primary care. Ann Fam Med. 2009;7(6):504-12.

27.Wandell PE, de Waard AM, Holzmann MJ, Gornitzki C, Lionis C, de Wit N, et al. Barriers and facilitators among health professionals in primary care to prevention of cardiometabolic diseases: A systematic review. Fam Pract. 2018;35(4):383-98.

28.Rubio-Valera M, Pons-Vigues M, Martinez-Andres M, Moreno-Peral P, Berenguera A, Fernandez A. Barriers and facilitators for the implementation of primary prevention and health promotion activities in primary care: a synthesis through meta-ethnography. PLoS One. 2014;9(2):e89554.

29.Butler CC, Simpson SA, Hood K, Cohen D, Pickles T, Spanou C, et al. Training practitioners to deliver opportunistic multiple behaviour change counselling in primary care: a cluster randomised trial. BMJ. 2013;346:f1191.

30.Huijg JM, Gebhardt WA, Dusseldorp E, Verheijden MW, van der Zouwe N, Middelkoop BJ, et al. Measuring determinants of implementation behavior: psychometric properties of a questionnaire based on the theoretical domains framework. Implement Sci. 2014;9:33.

31.Stevens C, Vrinten C, Smith SG, Waller J, Beeken RJ. Acceptability of receiving lifestyle advice at cervical, breast and bowel cancer screening. Prev Med. 2019;120:19-25.

32.Roura E, Castellsague X, Pawlita M, Travier N, Waterboer T, Margall N, et al. Smoking as a major risk factor for cervical cancer and pre-cancer: results from the EPIC cohort. Int J Cancer. 2014;135(2):453-66.

33. Hall S, Marteau TM. Practice nurses' self-reported opportunistic smoking cessation advice in three contexts. Nicotine Tob Res. 2007;9(9):941-5.

34.Kathuria H, Koppelman E, Borrelli B, Slatore CG, Clark JA, Lasser KE, et al. Patient-Physician Discussions on Lung Cancer Screening: A Missed Teachable Moment to Promote Smoking Cessation. Nicotine Tob Res. 2018.

35. Heiligers PJM, Noordman J, Korevaar JC. Kennisvraag: praktijkondersteuners in de huisartspraktijk (POH's), klaar voor de toekomst?. Utrecht: NIVEL, 2012; 2012.

36.van Dillen SM, Hiddink GJ. To what extent do primary care practice nurses act as case managers lifestyle counselling regarding weight management? A systematic review. BMC Fam Pract. 2014;15:197.

37. Hamilton K, Henderson J, Burton E, Hagger MS. Discussing lifestyle behaviors: perspectives and experiences of general practitioners. Health Psychology and Behavioral Medicine. 2019;7(1):290-307. 
38.Damschroder LJ, Aron DC, Keith RE, Kirsh SR, Alexander JA, Lowery JC. Fostering implementation of health services research findings into practice: a consolidated framework for advancing implementation science. Implement Sci. 2009;4:50.

\section{Supplementary Files}

This is a list of supplementary files associated with this preprint. Click to download.

- Additionalfile1.docx 